Tjalling C. Koopmans Research Institute

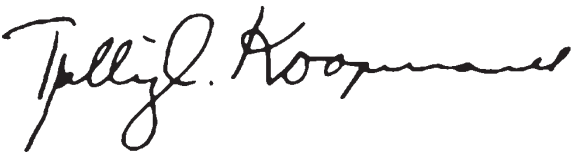

Discussion Paper Series nr: 10-07

\title{
Mean Reversion in International Stock Markets: An Empirical Analysis of the 20th Century
}

Laura Spierdijk Jacob A. Bikker

Pieter van den Hoek 


\section{Tjalling C. Koopmans Research Institute Utrecht School of Economics \\ Utrecht University}

Janskerkhof 12

3512 BL Utrecht

The Netherlands

telephone $\quad+31302539800$

fax $\quad+31302537373$

website www.koopmansinstitute.uu.nl

The Tjalling C. Koopmans Institute is the research institute and research school of Utrecht School of Economics.

It was founded in 2003, and named after Professor Tjalling C.

Koopmans, Dutch-born Nobel Prize laureate in economics of 1975.

In the discussion papers series the Koopmans Institute publishes results of ongoing research for early dissemination of research results, and to enhance discussion with colleagues.

Please send any comments and suggestions on the Koopmans institute, or this series to J.M.vanDort@uu.nl

ontwerp voorblad: WRIK Utrecht

\section{How to reach the authors}

Please direct all correspondence to the first author.

\section{Laura Spierdijk}

University of Groningen

Faculty of Economics \& Business

Department of Economics, Econometrics, \& Business

Centre for International Banking, Insurance and Finance

P.O. Box 800

NL-9700 AV Groningen

The Netherlands.

Email: I.spierdijk@rug.nl

\section{Jacob A. Bikker*}

Pieter van den Hoek (during the research for this paper)

De Nederlandse Bank (DNB)

Supervisory Policy Division

Strategy Department

P.O. Box 98

1000 AB Amsterdam

The Netherlands

E-mail: J.A.Bikker@DNB.nl

E-mail: $p$ vandenhoek@hotmail.com

*Utrecht University

Utrecht School of Economics

Janskerkhof 12

3512 BL Utrecht

The Netherlands.

This paper can be downloaded at: http:// www.uu.nl/rebo/economie/discussionpapers 


\title{
Mean Reversion in International Stock Markets: An Empirical Analysis of the 20th Century
}

\author{
Laura Spierdijk $k^{a}$ \\ Jacob A. Bikkerbc \\ Pieter van den Hoek ${ }^{b}$ \\ ${ }^{a}$ Faculty of Economics \& Business \\ University of Groningen \\ 'Supervisory Policy Division, Strategy Department \\ De Nederlandse Bank \\ 'Utrecht School of Economics \\ Utrecht University
}

March 2010

\begin{abstract}
This paper analyzes mean reversion in international stock markets during the period 1900-2008, using annual data. Our panel of stock indexes in seventeen developed countries, covering a time span of more than a century, allows us to analyze in detail the dynamics of the mean-reversion process. In the period 1900-2008 it takes stock prices about 13.8 years, on average, to absorb half of a shock. However, using a rolling-window approach we establish large fluctuations in the speed of mean reversion over time. The highest mean reversion speed is found for the period including the Great Depression and the start of World War II. Furthermore, the early years of the Cold War and the period covering the Oil Crisis of 1973, the

Energy Crisis of 1979 and Black Monday in 1987 are also characterized by relatively fast mean reversion. Overall, we document half-lives ranging from a minimum of 2.1 years to a maximum of 23.8 years. In a substantial number of time periods no significant mean reversion is found at all, which underlines the fact that the choice of data sample contributes substantially to the evidence in favor of mean reversion. Our results suggest that the speed at which stocks revert to their fundamental value is higher in periods of high economic uncertainty, caused by major economic and political events.
\end{abstract}

Keywords: mean reversion, market efficiency

JEL classification: C23, G14, G15 


\section{Introduction}

In early March 2009, many stock markets across the world dropped to their lowest value since the dot-com crisis. In less than two years, U.S. equity market indexes lost more than $50 \%$ of their value. At the time, a discussion was going on about future stock price movements. Some argued that when stocks are down over 50\%, an increase must surely follow. And the increase followed indeed. At the end of 2009, stock markets were up more than 30\% relative to March 2009. Looking back, it is tempting to think that the increase following the deep drop might have been expected.

The presence or absence of mean reversion has several important economic implications. Various studies show that excess returns can be earned by exploiting the mean reversion of stock prices (De Bondt \& Thaler 1985, 1987, Jegadeesh \& Titman 1993, Campbell \& Shiller 2001, Balvers et al. 2000, Gropp 2004). Moreover, in a study about pension fund regulation, Vlaar (2005) argues that mean reversion in stock prices would strongly increase the attractiveness of equity investments for pension funds. If stock prices are mean-reverting, low returns are followed by higher expected future returns, which could stimulate pension funds to invest in equity after a downfall of the stock market.

Do stock prices really exhibit mean-reverting behavior in the long run? For more than two decades the economic literature has attempted to answer this question. Although early studies document significant mean reversion, the general thought on the subject is that convincing evidence has yet to emerge.

The economic literature distinguishes between so-called absolute and relative mean reversion. With absolute mean reversion, stock prices are mean-reverting relative to an unspecified mean value. This is equivalent to negative autocorrelation in stock returns. Specifications based on relative mean reversion generally posit a direct relation between stock prices and fundamental indicators, such as dividends and earnings. Fama \& French (1988b) and Poterba \& Summers (1988) were the first to provide empirical evidence in favor of absolute mean reversion. Fama \& French (1988b) document that $25-40 \%$ of the variation in $3-5$ year stock returns can be attributed to negative serial correlation.

A major problem in analyzing mean reversion over long horizons is the limited amount of 
available data. Fama \& French (1988b) and Poterba \& Summers (1988) analyze the time period from 1926 to 1985, using yearly overlapping returns (based on monthly data) to increase the number of observations. Both studies base their results on long-term returns, with investment horizons between one and ten years. To deal with the issue of dependency, which is inherent in the use of overlapping observations, they apply the method of Hansen \& Hodrick (1980). However, this approach suffers from substantial small-sample bias. Richardson \& Smith (1991) show that the evidence for long-term mean reversion disappears if the small-sample bias is removed. Moreover, Fama \& French (1988b) ignore the seasonal effects in stock price movements. Jegadeesh (1991) shows that mean reversion in stock prices is entirely concentrated in January.

To circumvent the problems of overlapping samples and seasonality, Balvers et al. (2000) take a different approach. They focus on relative instead of absolute mean reversion. According to Balvers et al. (2000), the stationary relation between the fundamental value of a stock and a benchmark permits direct assessment of the speed of mean reversion. Moreover, they use annual instead of monthly data to avoid the problem of seasonality. Furthermore, to estimate the mean-reversion process more accurately, Balvers et al. (2000) adopt a panel data approach. Comparing the stock indexes of eighteen OECD countries to a world index benchmark during the period $1970-1996$, they establish significant mean reversion, with a half-life of approximately 3.5 years. The half-life measures the period it takes for stock prices to absorb half of a shock. Balvers et al. (2000) find a $90 \%$ confidence interval for the half-life equal to $(2.4,5.9)$ years.

Several arguments plead against the assumption of a constant speed of mean reversion. For example, Kim et al. (1991) conclude that mean reversion is a pre-war phenomenon only. Furthermore, Poterba \& Summers (1988) conclude that the Great Depression had a significant influence on the speed of mean reversion. Also the difference in the speed of mean reversion between our long sample period and the short interval considered by Balvers et al. (2000) suggests changes in the speed of mean-reversion over timee. Moreover, we may expect the speed of mean reversion to depend on the economic and political environment; see e.g. Kim et al. (1991). Consequently, the speed of mean reversion is expected to fluctuate over time. However, to our knowledge all previous studies in the field examine mean reversion in a static framework, thereby ignoring fluctuations in the speed of mean reversion over time. In our study we apply the panel data approach 
of Balvers et al. (2000) to a long data sample of international stock indexes, covering the period from 1900 to 2008. Our large sample of stock indexes in seventeen countries, covering a time span of more than a century, allows us to analyze in detail the dynamics of the mean-reversion process. In $1900-2008$ period, it takes stock prices on average 13.8 years to absorb half of a shock. However, using a rolling-window approach we establish large fluctuations in the speed of mean reversion over time. The highest speed of mean reversion is found for the period including the Great Depression and the start of World War II. Similarly, the early years of the Cold War and the period covering the Oil Crisis of 1973, the Energy Crisis of 1979 and Black Monday in 1987 also show relatively fast mean reversion. Overall, we document half-lives ranging from a minimum of 2.1 years to a maximum of 23.8 years. In a substantial number of time intervals no significant mean reversion is found at all, which underlines the fact that the choice of the data sample contributes substantially to the evidence in favor mean reversion. Our results suggest that stocks revert more rapidly to their fundamental value in periods of high economic uncertainty, caused by major economic and political events.

The remainder of this paper is organized as follows. Section 2 provides an overview of twenty years of research on the mean-reverting behavior of stock prices. The approach used in this paper to test for mean reversion is explained in Section 3. Next, Section 4 describes the data used for the empirical analysis of Section 5. The issue of time-varying mean reversion is addressed in Section 6. Finally, Section 7 concludes.

\section{Long-term mean reversion: 20 years of history}

Some studies have found evidence in favor of mean reversion, whereas others have established strong evidence against it. Several theories have been presented to explain mean reversion in stock prices. These explanations are strongly related to the issue of market efficiency. The efficient market hypothesis states that all available information is reflected in the value of a stock (Fama 1991). Mean reversion in stock prices may reflect market inefficiency. According to Poterba \& Summers (1988), mean reversion may be caused by the irrational behavior of noise traders, resulting in stock prices that take wide swings away from their fundamental value. Irrational pricing behavior, 
in turn, can be caused by fads (McQueen 1992, Summers 1986), overreaction to financial news (De Bondt \& Thaler 1985, 1987) or investor's opportunism (Poterba \& Summers 1988). Mean reversion in stock prices may also occur in efficient markets. Assuming that all available information is incorporated into stock prices, the value of a stock is determined by the expected returns per share. Consequently, mean reversion is observed when expected returns are mean-reverting (Summers 1986). Conrad \& Kaul (1988) find that the time-varying process of the expected return is stationary, i.e. it reverts to its mean over time. Therefore, mean reversion in stock prices does not contradict market efficiency (Fama \& French 1988b). Fluctuations in expected returns may be explained from uncertainty about the survival of the economy, caused by e.g. a world war or a depression (Kim et al. 1991). Fluctuations in expected returns may also be caused by rational speculative bubbles and uncertain company prospects can cause fluctuations in expected returns (McQueen 1992).

\subsection{Absolute mean reversion}

Fama \& French (1988b) were the first to document significant evidence in favor of absolute mean reversion at long horizons. They examine several investment horizons between one and ten years and document significant mean reversion, which explains $25-40 \%$ of the variation in $3-5$ year stock returns. Poterba \& Summers (1988) use a specific property of the random walk to obtain significant evidence in favor of mean reversion. They establish long-run mean reversion in the United States and several other developed countries. The lack of significance in their results is attributed to the absence of more powerful statistical tests to reject the null hypothesis.

Both Fama \& French (1988b) and Poterba \& Summers (1988) analyze the time period from 1926 to 1985 and work with yearly overlapping stock returns to increase the number of observations. The issue of dependency, which is inherent to the use of overlapping observations, is solved applying the method of Hansen \& Hodrick (1980). Richardson \& Smith (1991) criticize this approach and address the problem of small-sample bias. They show that the evidence supporting long-term mean reversion disappears if they remove the small-sample bias. Moreover, Richardson \& Stock (1990) argue that the use of a larger overlapping interval at longer investment horizons increases the power of the statistical tests used to test the random walk hypothesis. 
Their more powerful statistical test does not result in a rejection of the random walk hypothesis. Jegadeesh (1991) raises the issue of seasonality caused by the use use of monthly overlapping stock returns.

Apart from the issues related to the use of use of monthly overlapping stock returns, the results of Fama \& French (1988b) are also subject to other types of criticism. McQueen (1992) addresses the issue of heteroskedasticity in the sample period. The highly volatile years tend to have a larger influence on the results because of their relatively heavy weights. McQueen (1992) finds that the highly volatile periods exhibit stronger mean-reverting tendencies and that the overall evidence of mean reversion is therefore overstated. Kim \& Nelson (1998) and Kim et al. (1998) criticize Fama \& French (1988b) and Poterba \& Summers (1988) on similar grounds. The issue of heteroskedasticity is directly linked to another point of criticism. Periods of high volatility may not be representative of current stock price behavior. Poterba \& Summers (1988) note that the Great Depression has substantial influence on the estimates of the mean-reversion parameters. Excluding this period considerably weakens the evidence of mean reversion. Kim et al. (1991) divide the total sample period into a period before and a period after World War II and conclude that mean reversion is a pre-war phenomenon only. Furthermore, the post-war period reveals mean aversion, indicating a structural break in stock price behavior. ${ }^{1}$

\subsection{Relative mean reversion}

The lack of evidence for mean reversion is often attributed to small sample size in combination with statistical tests for mean reversion that lack power. A substantial improvement in estimation accuracy maybe achieved by explicitly specifying the fundamental value process around which stock prices are mean-reverting. An important question is how to proxy the fundamental value process, which is inherently unobserved. According to the Gorden growth model, the value of a stock equals the discounted future cash flows generated by the stock (Gorden 1959). In practice, these cash flow are the dividends that will be paid out to the owners. As an alternative to estimating future dividends, earnings could be used as a proxy of future cash flows towards investors. Other possible proxies are valuation ratios, such as dividend yield or price-earnings ratios. Campbell \& Shiller (2001) examine the mean-reverting behavior of the dividend yield and 
price-earnings ratio over time. Theoretically, these ratios are expected to be mean-reverting, since fundamentals are determinants of stock prices. If stock prices are high in comparison to company fundamentals, it is expected that an adjustment to either stock prices or fundamentals will follow. Campbell \& Shiller (2001) find that stock prices rather than company fundamentals contribute most to adjusting the ratios towards an equilibrium level. Coakley \& Fuertes (2006) consider the mean-reverting behavior of valuation ratios and attribute it to differences in investor sentiment. The authors conclude that in the long run financial ratios revert to their mean. In earlier work, Fama \& French (1988a) link the dividend yield to the expected returns of a stock and find that the latter have a mean-reverting tendency. A second specification of fundamental value is based on asset pricing models. Ho \& Sears (2004) link the mean-reverting behavior of stocks to the Fama-French three factor model and conclude that such models cannot capture the mean-reverting behavior of stock prices. Similar conclusions emerge from Gangopadhyay \& Reinganum (1996). However, they argue that mean reversion can be explained by the CAPM if the market risk premium is allowed to vary over time. Note that this fluctuation is in accordance with the theoretical explanation of mean reversion in efficient markets; expected returns fluctuate in a mean-reverting manner (Summers 1986). Gropp (2004) argues that valuation ratios are inherently flawed, because information on company fundamentals cannot be compared to stock prices due to the delay in adjustment. Expected future dividends and earnings influence fundamental value, which cannot be captured by the current dividend yield or price-earnings ratio. Moreover, the loss of information due to the use of proxies may contribute to the failure to recognize mean-reverting behavior.

\section{Mean reversion model}

We consider the stock market indexes of $N$ countries, observed over $T$ years. Each stock index is expected to revert to its intrinsic value in the long run. In line with Balvers et al. (2000), we assume a mean-reverting process for each country $i$ :

$$
r_{t+1}^{i}=a^{i}+\lambda^{i}\left(p_{t+1}^{* i}-p_{t}^{i}\right)+\varepsilon_{t+1}^{i},
$$


where $r_{t+1}^{i}$ equals the continuously compounded return on the stock index of country $i$ between time $t$ and $t+1, p_{t+1}^{* i}$ is the natural logarithm of the intrinsic value of the stock index of country $i$ at time $t+1$ and $p_{t}^{i}$ is the natural logarithmic stock index of country $i$ at time $t$. The error term $\varepsilon_{t}^{i}$ is assumed to be a country-specific stationary process with unconditional mean zero. Parameter $a^{i}$ is a country-specific constant and $\lambda^{i}$ indicates the speed of reversion of the index price process of country $i$. The relation between the index return and the deviation from its fundamental value depends entirely on parameter $\lambda^{i}$. The process in Equation (1) is a mean-reverting process if $0<\lambda^{i}<1$. Mean aversion occurs for $\lambda^{i}<0$.

To estimate the parameters $a^{i}$ and $\lambda^{i}$ directly, we have to know the fundamental value $p_{t}^{* i}$. Unfortunately, due to the difficulty of determining firms' intrinsic value, this value can generally not be measured. Like Balvers et al. (2000), we assume that the difference in intrinsic value between the natural logarithm of the stock index $\left(p_{t}^{* b}\right)$ and the natural logarithm of the benchmark index $\left(p_{t}^{* b}\right)$ is a stationary process. ${ }^{2}$ We assume the benchmark $b$ to be defined in such a way that for all countries $i$ the following holds:

$$
p_{t}^{* i}-p_{t}^{* b}=c^{i}+\xi_{t}^{i}
$$

where $c^{i}$ is a country-specific constant and $\xi_{t}^{i}$ is a zero-mean stationary process. The stationary process $\xi_{t}^{i}$ of Equation (2) may be serially correlated over time, as well as correlated across countries. Furthermore, we assume that the stock index benchmark follows the mean-reverting process of Equation (1) and that the reversion speed parameter $\lambda^{i}$ is constant across all countries (i.e. $\lambda^{i}=\lambda$ ). The latter assumption does not imply that the mean-reversion process is synchronized across countries. Only the speed at which stock prices revert to their fundamental values is the same (Balvers et al. 2000). With the mean reversion speed constant across countries, it is possible to adopt a panel data approach. One advantage of such an approach is the large increase in sample size and the substantial increase in the power to test the null hypothesis $\lambda=0$ (corresponding to no mean reversion).

Consider the differences between the returns of country $i$ and benchmark $b$ at time $t+1$ :

$$
r_{t+1}^{i}-r_{t+1}^{b}=\alpha^{i}-\lambda\left(p_{t}^{i}-p_{t}^{b}\right)+\psi_{t+1}^{i},
$$


where $r_{t+1}^{b}$ equals the continuously compounded return on the benchmark index between time $t$ and $t+1, \alpha^{i}=a^{i}-a^{b}+\lambda c^{i}$ is a country-specific constant, and $\psi_{t+1}^{i}=\varepsilon_{t+1}^{i}-\varepsilon_{t+1}^{b}+\lambda \xi_{t+1}^{i}$ is the error term. Process $\psi_{t}^{i}$ consists of two zero-mean stationary processes, whose statistical properties it inherits. In particular, $\psi_{t}^{i}$ is allowed to be correlated over time and across countries. All variables in Equation (3) are observable from historical data, and therefore the country-specific constants and the speed of reversion $\lambda$ can be estimated. To deal with serial correlation, $k$ lagged return differentials are added to the equation. Choosing the right value of $k$ (using e.g. Bayesian information criterion) results in a significant purge of autocorrelation in the returns. Thus, the adjusted model becomes

$$
r_{t+1}^{i}-r_{t+1}^{b}=\alpha^{i}-\lambda\left(p_{t}^{i}-p_{t}^{b}\right)+\sum_{j=1}^{k} \phi_{j}^{i}\left(r_{t-j+1}^{i}-r_{t-j+1}^{b}\right)+\omega_{t+1}^{i} .
$$

Equation (4) boils down to a cointegration model, according to which the stock market index in country $i$ is cointegrated with the benchmark index for $\lambda \neq 0$. We can estimate the model in Equation (4) using seemingly unrelated regression (SUR); see e.g. Johnston \& DiNardo (1997). However, the estimated model coefficients are generally biased and the bias may be severe (Andrews \& Chen 1994). Therefore, we proceed as in Andrews \& Chen (1994) and use a bootstrap approach to obtain an (approximately) mean-unbiased estimate of $\lambda$, the model coefficient of interest, and a corresponding 95\% confidence interval for the purpose of statistical inference. In contrast to the Monte Carlo approach employed by Balvers et al. (2000), we do not impose normality on the model residuals. As stock returns are generally found to be fat-tailed, we follow a non-parametric approach and simply bootstrap from the empirical distribution of the model innovations. For more details about our bootstrap approach we refer to Appendix A.

\section{Data}

Shortly after the second millennium, Dimson et al. (2002) published a book on the financial history of 17 countries with historically well-developed economies and financial markets. The countries included are Australia, Belgium, Canada, Denmark, France, Germany, Ireland, Italy, Japan, the Netherlands, Norway, South-Africa, Spain, Sweden, Switzerland, United Kingdom and the United 
States. The authors collected annual equity, bond and treasury bill investment data from all over the world over a long horizon. With the aid of many local specialists, they determined the most exact index value possible for each of the 101 years from 1900 to 2000, adjusted for inconsistencies. In addition, they constructed a world index from the values of the country indexes. ${ }^{3}$ Every year the authors present an extension of the data, cumulating in an uninterrupted series of 109 yearly stock market returns up to the year 2008. Table 1 gives the mean, the standard deviation, the skewness and the kurtosis of the annualized continuously compounded nominal returns on the stock values between 1900 and 2008 in US dollars. Also shown is the beta coefficient with the world index.

The largest historical return over the full period is found for Sweden, followed closely by the Australian market, with average yearly returns of $9.9 \%$ and $9.7 \%$, respectively. The lowest average for the full period is found for Italy, where a mean return of $5.1 \%$ was realized. The most volatile markets are Germany and Japan. In the years that ended World War I (1918) and World War II (1945), Germany suffered extreme declines in its market prices: $73 \%$ and $79 \%$, respectively. In each case, the stock market regained the losses a number of years later; during 1923 and 1948 the German stock market skyrocketed by a striking $338 \%$ and $700 \%$, respectively. The fluctuations during these historically critical years cause the standard deviations to rise substantially. Similar findings apply for the Japanese equity market index. The lowest volatility is observed in Canada, followed by Switzerland and the United States.

The skewness of most countries is negative, which indicates higher volatility in negative returns. Especially Japan and France show relatively high volatility when stock markets decline. The excess kurtosis measures the deviation of the kurtosis from three. In case the excess kurtosis equals zero, the tails of the return distribution are comparable to those of a normal distribution. Where the excess kurtosis is zero, the tails of the return distribution are comparable to those of a normal distribution. Where the excess kurtosis much greater than zero, the return distribution exhibits fat tails. The market index of the United States has the lowest kurtosis; its value of 3.7 indicates that the tails of the return distribution are comparable to a normal distribution. The obvious outlier in excess kurtosis is Japan with a kurtosis of 21.3. Germany follows with a kurtosis of 9.1.

The last column of Table 1 displays the beta coefficient with respect to the world index. The beta describes the relation between the returns on the country index and the returns on the world 
index. The lowest beta value is obtained for Spain (0.71) and the highest for Germany (1.13).

\section{Empirical results}

Before estimating the panel data model as introduced in Section 3, we compare each country's index returns individually to a benchmark. This approach allows us to estimate country-specific values of the mean-reversion parameter $\lambda^{i}$.

\subsection{Individual countries}

The first column of Table 2 provides the country-specific estimates $\hat{\lambda}_{0}^{i}$ based on SUR estimation, with corresponding 95\% confidence intervals obtained from the augmented Dickey-Fuller test applied to Equation (4). The bootstrap approach (see Appendix A) has been used to obtain median-unbiased estimates of $\hat{\lambda}^{i}$ (see Section 3), which are reported in the third column of Table 2 . The corresponding 95\% confidence intervals are reported in the fourth column of Table 2 . The estimates in the first column are all positive, but not significantly different from zero (at the $5 \%$ significance level). The biased estimates are substantially larger than the median-unbiased estimates based on the bootstrap method. The main result from Table 2 is that the median-unbiased estimates are not significantly different from zero. Hence, for no country do we find evidence in favor of mean reversion. A second important result emerging from Table 2 is that the speed of mean reversion does not differ significantly across countries.

Table 2 provides estimates based on the world index benchmark. By contrast, Table 3 considers four different benchmarks for the stock indexes: the indexes for the United States, Japan, France and Germany. For one out of four benchmarks, significant mean reversion is found for Belgium, Denmark, Norway, Sweden and South-Africa. For all remaining countries the estimated speed of mean reversion as reported in Table 3 is not significantly different from zero. Moreover, the estimates do not significantly differ across the four different benchmark countries. These conclusions underline that the choice of benchmark hardly affects the estimated speed of mean reversion. 


\subsection{Panel data approach}

Despite our sample period of more than a century, we do not find any significant evidence for mean reversion at the country level. A serious problem with hypothesis testing in cointegration models is the low power of these tests, particularly in relatively small samples. In our particular case we may fail to reject the null hypothesis of no mean reversion simply because our tests lack statistical power. To improve the significance of our estimation results, we apply the panel data model described in Section 3 to the data of Dimson et al. (2002). The panel data model is estimated under the assumption that the speed of mean reversion is the same in all countries under consideration. The lack of significant differences in the speed of mean reversion across countries justifies this assumption. Again the bootstrap method is applied to obtain a mean-unbiased bootstrap estimate of the speed of mean reversion.

Table 4 presents the estimates $\hat{\lambda}_{0}$ based on SUR estimation. Also the median-unbiased estimates $\hat{\lambda}$ are included in the table, along with $95 \%$ confidence intervals. In addition to the speed of mean reversion, the half-life of the mean-reversion process is determined and reported (also in combination with $95 \%$ confidence intervals). This half-life is calculated as $\log 0.5 / \log (1-\lambda)$, where $\lambda$ is taken to be the median-unbiased estimate. ${ }^{4}$

Again we examine the sensitivity of the results to the choice of benchmark. First consider the world index as the benchmark. The biased speed of mean reversion $\hat{\lambda}_{0}$ over the full period equals 0.0668 . The median-unbiased estimate of the speed of reversion $\hat{\lambda}$ is 0.0491 . To interpret this number, consider the initial model of Equation (1), where stock returns are assumed to be a function of the deviation from the intrinsic value. The positive value of $\hat{\lambda}$ implies that a positive deviation between stock price and intrinsic value in this period will result in a negative expected return in the next period. Moreover, the value of lambda reflects the speed at which the price reverts to its fundamental value. Each year a price correction takes place of $4.9 \%$ of the logarithmic price deviation from the fundamental value. In order to measure the speed of mean reversion in years, the half-life of a gap between stock price and intrinsic value is considered. Notice that a higher speed of reversion implies a shorter half-life. With the world index as benchmark, the half-life of a price deviation is 13.8 years. In other words, $50 \%$ of a shock to the stock price will be offset in 13.8 years after occurrence. The $95 \%$ confidence interval has a lower bound equal to 10.1 years 
and an upper bound of 21.1 years. The values corresponding to the four other benchmarks are similar.

Balvers et al. (2000) establish significant mean reversion during the period $1970-1996$. Their

value of the unbiased estimate $\hat{\lambda}$ equals 0.182 (90\% confidence interval $[0.110,0.250])$, which implies a half-life of 3.5 years (90\% confidence interval $[2.4,5.9]$ years). Their results with the U.S. benchmark index are of a similar magnitude; the unbiased estimate of $\lambda$ equals 0.202 , implying a half-life of 3.1 years. Our unbiased estimates of the speed of mean reversion, based on a sample period of more than a century, differ substantially from the results established in Balvers et al. (2000), based on less than three decades only. We document a much lower speed of mean reversion and a much longer half-life. ${ }^{5}$

\section{Time-varying mean reversion}

With our panel data model we establish a half-life of 13.8 years for the full sample period, covering the years $1900-2008$. Several arguments plead against the assumption of a constant speed of mean-reversion. For example, Kim et al. (1991) conclude that mean reversion is a pre-war phenomenon only. Furthermore, Poterba \& Summers (1988) conclude that the Great Depression had a significant influence on the speed of mean reversion. Also the difference in the speed of mean reversion between our long sample period and the short interval considered by Balvers et al. (2000) suggests changes in the speed of mean-reversion over time.

\subsection{Rolling window approach}

Our large panel data set allows us to analyze the speed of mean reversion during multiple smaller time intervals. For this purpose, we apply a rolling window estimation approach to (overlapping) time intervals of 27 years. The choice of the rolling window width is crucial. Too small a window will result in very erratic results, but too large a window will yield too smooth results. Eyeballing makes clear that a window width around 30 years works well. Eventually, we opt for a window width of 27 years. The length of this interval is in accordance with Balvers et al. (2000), who consider the years $1970-1996$, facilitating comparison of our results to theirs. 
Table 5 displays the biased and unbiased estimates of reversion speed, based on 83 rolling windows of 27 yearly returns. The corresponding 95\% confidence intervals are provided as well, based on the aforementioned bootstrap method. Clearly, the mean-reversion coefficient $\lambda$ is not constant over time. Its largest value is 0.284 , observed during the period 1918-1944. The lowest value is obtained for the interval $1901-1927$ and equals 0.029 , which is almost 10 times smaller. The two intervals have a half-life of 2.1 and 23.6 years, respectively. An important issue is the significance of mean reversion. All periods without statistically significant mean reversion include one or more years before 1940 .

To visualize the speed of mean reversion over time, Figure 1 displays the median-unbiased rolling-window estimates of the speed of mean reversion, in combination with $95 \%$ confidence intervals. Figure 2 displays the corresponding half-life for the period 1900-2008, whereas Figure 3 shows the half-life and a corresponding 95\% confidence interval for the post-war period 1946-2008. Throughout, the rolling-window estimates are plotted against the mid-year of the 27-year rolling-window period. In Figure 1, a horizontal line is drawn at the critical value zero.

It is difficult to attribute differences in the speed of mean reversion between two time intervals to one specific year. Consider for example the last two intervals, $1981-2007$ and $1982-2008$. The corresponding half-lives of the intervals are, respectively, 6.9 and 3.8 years. The decrease in half-life by 3.1 years reflects the overall effect of adding an additional year to the rolling-window interval and leaving one year out. Notice that the interval 1982-2008 takes into account the start of the financial crisis in the year 2008.

A more appealing interpretation can be found by studying Figure 1. Focusing on the periods between 1924 - 1950 and 1939 - 1965, where no significant mean reversion is observed, we see that the years 1939 - 1950 are used for all rolling-window estimates during this period. This suggests this period includes some years of extremely slow, if any, mean reversion. The only major political event during these years is World War II. In the first peak in Figure 1 there are seven values remarkably larger than others. These points correspond to the seven rolling-window periods between 1914-1940 and 1920 - 1946. All seven intervals include the period 1920-1940, during which the Great Depression and the start of World War II took place. The second peak in Figure 1 is observed for the periods between 1941-1967 and 1951-1977. The years 1951-1967 
are used for all rolling-window estimates during this period and correspond to an era with a lot of tension related to the Cold War (such as the Berlin Crisis of 1961 and the Cuba Crisis of 1962), as well as the wars in Korea $(1950-1953)$ and Vietnam $(1959-1975)$. The third peak in Figure 1 is less pronounced than the other two, but still clearly visible. It is observed for the periods between 1968 - 1994 and $1974-2000$. The years $1974-1994$ are used for all rolling-window estimates during this period. The Energy Crisis of 1979 occurred during this period, as well as Black Monday in 1987. Furthermore, the Oil Crisis of 1973 is used for all rolling-window estimates during this period, except the last one.

Turning to Figure 2, we see that the differences in half-life between the periods before and after mid-year 1953 are substantial. The post-1953 period exhibits significant mean reversion with relatively short half-lives, unlike the preceding period, where over $50 \%$ of the estimates of the mean-reversion speed are insignificant, with relatively long half-lives. After mid-year 1953, the average half-life is shorter and the variability of the estimates is much lower. All estimates before mid-year 1953 include the 1926 - 1940 interval, whereas all post-1953 estimates incorporate the years 1967 - 1982. The years 1926 - 1940 contain the Great Depression as the major economic event, as well as the first year of World War II. During the period 1967 - 1982 the major political and economic events were more ample: the tension related to the Cold War, the Vietnam War (1959 - 1975), the Oil Crisis (1973), and the Energy Crisis (1979). ${ }^{6}$

\subsection{Economic explanation for time-varying mean reversion}

Our results suggest that the speed at which stock prices revert to their fundamental value is higher in periods of high economic uncertainty, caused by major events such as the Great Depression, World War II, and the Cold War. We provide two explanations. In Section 2 we already mentioned that mean reversion in stock prices may occur in efficient markets. Assuming market efficiency, the value of a stock is determined by the expected returns per share. Consequently, mean reversion is observed when expected returns are mean reverting (Summers 1986). Deviations in expected returns from their long-term value may be explained from uncertainty about the survival of the economy, caused by e.g. a world war or a depression (Kim et al. 1991). Our findings suggest that expected returns diverge away from their long-term value and converge back to this level relatively 
quickly during periods of high economic uncertainty; much faster than in more tranquil periods. When the economic uncertainty dissolves, expected returns are likely to show a substantial increase in value during a relatively short time period, which could account for such high mean reversion speed. Measures and interventions by financial and government institutions to restore financial stability may also speed up the adjustment process. Outside the framework of efficient markets, mean reversion may be caused by the irrational behavior of noise traders, resulting in stock prices that take wide swings away from their fundamental value (Poterba \& Summers 1988). Irrational pricing behavior, in turn, can be caused by overreaction to financial news (De Bondt \& Thaler 1985, 1987). Our results could imply that noise traders overreact heavily to (financial) news in periods of high economic uncertainty. This may work in two directions. At the start of the uncertainty, the overreaction to bad news may take stock prices far below their fundamental value. During recovery, noise traders tend to overreact to the good news, resulting in stock prices far above their fundamental value. In both cases, large price swings in relatively little time result in rapid mean reversion.

Clearly, the nature of our analysis only permits us to suggest that the mean reversion speed is higher in periods of high economic uncertainty. Similarly, our explanations are merely a first attempt to explain this phenomenon. We leave further analysis of this issue as an important topic for future research.

\section{Conclusions}

This study analyzes mean reversion in international stock markets during the $1900-2008$ period, using annual data. Our panel of stock indexes in seventeen developed countries, covering a timespan of more than a century, allows us to analyze in detail the dynamics of the mean-reversion process. In the period 1900-2008 it takes stock prices about 13.8 years, on average, to absorb half of a shock. However, using a rolling-window approach we find large fluctuations in the speed of mean reversion over time. The highest speed of mean reversion is found for the period including World War I, the Great Depression and the start of World War II. Also the early years of the Cold War and the period covering the Oil Crisis of 1973, the Energy Crisis of 1979 and Black Monday in 
1987 are characterized by relatively rapid mean reversion. Overall, we document half-lives ranging from 2.1 years to 23.8 years. In a substantial number of periods no significant mean reversion is found at all, which underlines the fact that the choice of data sample contributes substantially to the evidence in favor mean reversion.

How can we explain time-varying mean-reversion in stock prices? Our results suggest that the speed at which stocks revert to their fundamental value is higher in periods of high economic uncertainty caused by major events such as the Great Depression, World War II and the Cold War. In both efficient and inefficient markets, large price movements in relatively short time may account for the a high mean reversion speed.

A time-varying speed of mean reversion has important economic implications. For example, several studies show that excess returns can be earned by exploiting mean reversion of stock prices (De Bondt \& Thaler 1985, 1987, Jegadeesh \& Titman 1993, Campbell \& Shiller 2001, Balvers et al. 2000, Gropp 2004). However, such a trading strategy implies that a mean-reversion parameter has to be chosen. Our results show that the estimated speed of mean-reversion depends crucially on the sample period. In some time periods the mean-reversion parameter even turns out insignificant. The low value of the mean reversion parameter, as well as its huge uncertainty, severely limits the possibilities to exploit mean reversion in a trading strategy. 


\section{Notes}

${ }^{1}$ Mean aversion is movement of stock prices away from their mean value over time.

${ }^{2}$ This assumption cannot be tested empirically since both intrinsic values are unobservable. However, Balvers et al. (2000) justify the assumption using an economic explanation based on the convergence of per capita GDP. Real per capita GDP across 20 OECD countries display absolute convergence, which means that real per capital GDP converges to the same steady state (Barro \& Sala-i Martin 1995). According to the authors, absolute convergence results from the fact that countries catch up in capital and technology. Developed countries are expected to catch up in capital because lower per capita GDP implies a larger marginal efficiency of investment (Barro 1991). Catching up in technology occurs because adapting an existing technology is cheaper than inventing a new one (Barro \& Sala-i Martin 1995). The connection between stock index convergence and GDP convergence is imposed by Balvers et al. (2000). Validity of this argument can be found in a country index that represents the general state of the stock market. Assuming a direct relation between the intrinsic value of the stock market and companies generating the gross domestic product justifies the assumption of stationarity between the country's fundamental stock price indexes.

${ }^{3}$ The world index is a size-weighted portfolio of all country's indexes. The weights before 1968 are based on GDP due to a lack of reliable data on capitalization prior to that date. The weights from 1968 onwards are based on market capitalizations published by Morgan Stanley Capital International (MSCI). The sizes are annually adjusted to the GDP or market capitalization at the beginning of the year. (Dimson et al. 2002, pg. 311)

${ }^{4}$ Consider a model of the form

$$
p_{t}=p_{t}^{*}+z_{t}
$$

where $z_{t}=\phi z_{t-1}+\eta_{t}$ is a stationary $\mathrm{AR}(1)$ process. Error term $\eta_{t}$ is assumed to be a zero-mean stationary process. In this specification, the permanent component $p_{t}^{*}$ models the intrinsic value of the stock. Any shock to the permanent component at time $t$ is incorporated completely into the future stock price. Furthermore, the temporary component $z_{t}$ models the mean-reverting part of the price. In such a model (where the temporary component has an autoregressive structure), the half-life is defined as $\log 0.5 / \log \psi$. The mean-reverting process that we consider in this paper has the form

$$
p_{t}=p_{t-1}+a+\lambda\left(p_{t}^{*}-p_{t-1}\right)+\epsilon_{t} .
$$

Such a model can be directly derived from Equation 5. Define $\lambda=(1-\phi)$ and $\epsilon_{t}=(1-\lambda) \delta_{t}+\eta_{t}$ and substituting 
the specific incremental value process $p_{t}^{*}$ for $p_{t-1}^{*}+\delta_{t}$, as follows:

$$
\begin{aligned}
p_{t} & =p_{t}^{*}+z_{t}=p_{t-1}^{*}+\delta_{t}+a+\phi z_{t-1}+\eta_{t} \\
& =p_{t-1}^{*}+\delta_{t}+a+(1-\lambda) \cdot\left(p_{t-1}-p_{t-1}^{*}\right)+\eta_{t} \\
& =p_{t}^{*}+a+p_{t-1}-\left(p_{t}^{*}-\delta_{t}\right)-\lambda\left(p_{t-1}-\left(p_{t}^{*}-\delta_{t}\right)\right)+\eta_{t} \\
& =a+p_{t-1}+\lambda\left(p_{t}^{*}-p_{t-1}\right)+(1-\lambda) \delta_{t}+\eta_{t}=p_{t-1}+a+\lambda\left(p_{t}^{*}-p_{t-1}\right)+\epsilon_{t}
\end{aligned}
$$

Up to a constant, the price at time $t$ equals the price at time $t-1$, adjusted for the deviation between the fundamental price at time $t$ and the stock price at time $t-1$. Notice that the mean process $p_{t}^{*}$ is explicit in this model and that mean reversion implies reversion towards the specific mean. The half-life of the stationary process in Equation (5) is calculated by $\log 0.5 / \log \phi$, with $\phi=1-\lambda$, which leads to the formula to calculate the half-life in this section. Since the half-life is a monotonic transformation of the mean reversion parameter $\lambda$, a median-unbiased estimator for the half-life is simply obtained as $\log 0.5 / \log (1-\hat{\lambda})$ where $\hat{\lambda}$ is the median-unbiased estimator for $\lambda$. Similarly, the $97.5 \%$ quantile for the half-life is obtained by taking the half-life transformation of the $2.5 \%$ quantile for the speed of mean reversion. Notice that the the half-life is only defined for $\lambda>0$; the half-life converges to infinity for $\lambda \downarrow 0$.

${ }^{5}$ Balvers et al. (2000) estimate the speed of reversion for the period $1970-1996$ in a similar fashion as we do. However, they use a Monte Carlo simulation to obtain median-unbiased estimators, assuming multivariate normality of the residuals of the time series model in Equation (4). Moreover, their empirical analysis is based on the Morgan Stanley Capital International (MSCI) for stock market price indexes of 18 countries. These countries are Australia, Austria, Belgium, Canada, Denmark, France, Germany, Hong Kong, Italy, Japan, the Netherlands, Norway, Singapore, Spain, Sweden, Switzerland, the United Kingdom, and the United States. Notice that in our data set, we have SouthAfrica instead of Austria and Singapore, due to different choices made by the data collectors. For the period 1970-1996 as considered by Balvers et al. (2000), we establish a mean reversion speed equal to 0.218 . This number is very close to their speed of 0.182 , confirming that the small difference in countries does not substantially affect the results.

${ }^{6}$ Notice that the uncertainty around the last six rolling-window estimates of the half-lives in Figure 3 is very large. This is due to the fact that the lower bounds for the corresponding median unbiased estimators are close to zero; the upper bounds of the confidence intervals for the half-lives are therefore very high. 


\section{References}

Andrews, D. \& Chen, H.-Y. (1994), 'Approximately mean-unbiased estimation of autoregressive models', Journal of Business and Economic Statistics 12, 187-203.

Balvers, R., Wu, Y. \& Gilliland, E. (2000), 'Mean reversion across national stock markets and parametric contrarian investment strategies', Journal of Finance 55, 745-772.

Barro, R. (1991), 'Economic growth in a cross section of countries', The Quarterly Journal of Economics 106, 407-443.

Barro, R. \& Sala-i Martin, X. (1995), Economic Growth, McGraw-Hill.

Boudoukh, J., Richardson, M. \& Whitelaw, R. (2008), 'The myth of long-horizon predictability', Review of Financial Studies 21, 1577-1605.

Campbell, J. \& Shiller, R. (2001), Valuation ratios and the long-run stock market outlook: An update, Nber working papers, National Bureau of Economic Research, Inc.

Coakley, J. \& Fuertes, A.-M. (2006), 'Valuation ratios and price deviations from fundamentals', Journal of Banking \& Finance 30, 2325-2346.

Conrad, J. \& Kaul, G. (1988), ‘Time-variation in expected returns', Journal of Business 61, 409_ 425.

De Bondt, W. \& Thaler, R. (1985), 'Does the stock market overreact?', Journal of Finance 40, 793-805.

De Bondt, W. \& Thaler, R. (1987), 'Further evidence on investor overreaction and stock market seasonality', Journal of Finance 42, 557-581.

Dimson, E., Marsh, P. \& Staunton, M. (2002), Triumph of the Optimists: 101 Years of Global Investment Returns, Princeton University Press.

Fama, E. (1991), 'Efficient capital markets: Ii’, Journal of Finance 46, 1575-1617. 
Fama, E. \& French, K. (1988a), 'Dividend yields and expected stock returns', Journal of Financial Economics 22, 3-25.

Fama, E. \& French, K. (1988b), 'Permanent and temporary components of stock prices', Journal of Political Economy 96, 246-273.

Gangopadhyay, P. \& Reinganum, M. (1996), 'Interpreting mean reversion in stock returns', The Quarterly Review of Economics and Finance 36, 377-394.

Gorden, M. (1959), 'Dividends, earnings and stock prices', Review of Economics and Statistics 41, 99-105.

Gropp, J. (2004), 'Mean reversion of industry stock returns in the u.s., 1926-1998', Journal of Empirical Finance 11, 537-551.

Hansen, L. \& Hodrick, R. (1980), 'Forward exchange rates as optimal predictors of future spot rates: An econometric analysis', Journal of Political Economy 88, 829-853.

Ho, C.-C. \& Sears, R. (2004), 'Dividend yields and expected stock returns', Quarterly Journal of Business \& Economics 45, 91-112.

Jegadeesh, N. (1991), 'Seasonality in stock price mean reversion: Evidence from the u.s. and the u.k', Journal of Finance 46, 1427-1444.

Jegadeesh, N. \& Titman, S. (1993), 'Returns to buying winners and selling losers: Implications for stock market efficiency', Journal of Finance 48, 65-91.

Johnston, J. \& DiNardo, J. (1997), Econometric Methods, McGraw-Hill.

Kim, C.-J. \& Nelson, C. (1998), 'Testing for mean reversion in heteroskedastic data ii: Autoregression tests based on gibbs-sampling-augmented randomization', Journal of Empirical Finance 5, 385-396.

Kim, C.-J., Nelson, C. \& Startz, R. (1998), 'Testing for mean reversion in heteroskedastic data based on gibbs-sampling-augmented randomization', Journal of Empirical Finance 5, 131-154. 
Kim, M., Nelson, C. \& Startz, R. (1991), 'Mean reversion in stock prices? a reappraisal of the empirical evidence', Review of Economic Studies 58, 515-528.

McQueen, G. (1992), 'Long-horizon mean-reverting stock prices revisited', Journal of Financial and Quantitative Analysis 27, 1-18.

Poterba, J. \& Summers, L. (1988), 'Mean reversion in stock prices: Evidence and implications', Journal of Financial Economics 22, 27-59.

Richardson, M. (1993), ‘Temporary components of stock prices: A skeptic's view', Journal of Business \& Economic Statistics 11, 199-207.

Richardson, M. \& Smith, T. (1991), 'Tests of financial models in the presence of overlapping observations', Review of Financial Studies 4, 227-254.

Richardson, M. \& Stock, J. (1990), Drawing inferences from statistics based on multi-year asset returns, Nber working papers, National Bureau of Economic Research, Inc.

Summers, L. (1986), 'Does the stock market rationally reflect fundamental values?', Journal of Finance 41, 591-601.

Vlaar, P. (2005), Defined benefit pension plans and regulation, DNB working papers, Dutch Central Bank, Research Department. 
Table 1: Summary statistics for the index returns during the period $1900-\mathbf{2 0 0 8}$.

\begin{tabular}{lccccc}
\hline & Mean & $\begin{array}{c}\text { Standard } \\
\text { Deviation }\end{array}$ & Skewness & $\begin{array}{c}\text { Excess } \\
\text { Kurtosis }\end{array}$ & $\begin{array}{c}\text { Beta with } \\
\text { World Index }\end{array}$ \\
& & & & & \\
Australia & 0.097 & 0.219 & -0.879 & 2.408 & 0.903 \\
Belgium & 0.055 & 0.237 & -0.074 & 1.278 & 0.945 \\
Canada & 0.085 & 0.185 & -0.892 & 2.092 & 0.932 \\
Denmark & 0.081 & 0.210 & -0.281 & 2.699 & 0.804 \\
France & 0.061 & 0.284 & -1.034 & 4.337 & 1.052 \\
Germany & 0.061 & 0.433 & 0.429 & 6.076 & 1.134 \\
Ireland & 0.068 & 0.243 & -0.740 & 4.208 & 0.959 \\
Italy & 0.051 & 0.302 & -0.117 & 1.458 & 1.015 \\
Japan & 0.072 & 0.376 & -3.018 & 18.29 & 0.876 \\
The Netherlands & 0.079 & 0.236 & -0.952 & 4.654 & 0.889 \\
Norway & 0.069 & 0.275 & -0.209 & 2.704 & 0.826 \\
South-Africa & 0.088 & 0.251 & 0.234 & 1.246 & 0.788 \\
Spain & 0.066 & 0.258 & -0.229 & 1.005 & 0.710 \\
Sweden & 0.099 & 0.247 & -0.697 & 1.161 & 1.008 \\
Switzerland & 0.078 & 0.187 & 0.066 & 1.016 & 0.753 \\
UK & 0.077 & 0.220 & -0.568 & 2.675 & 1.027 \\
US & 0.088 & 0.196 & -0.879 & 0.741 & 1.026 \\
World & 0.080 & 0.167 & -0.915 & 1.949 & 1.000 \\
& & & & & \\
\hline & & & & &
\end{tabular}


Table 2: Speed of mean reversion for individual countries (benchmark: World Index)

This table reports the country-specific estimates of the speed of mean reversion, based on the World Index as benchmark. The sample period covers the years 1900-2008. The biased SUR estimate of the speed of mean reversion is reported ( ${ }^{i}{ }_{0}^{i}$,), together with a $95 \%$ confidence interval ('95\% C.I.). Also the median-unbiased estimate (' $\lambda^{i}$ ') is provided, in combination with a corresponding $95 \%$ confidence interval based on the bootstrap approach ('95\% C.I.).

\begin{tabular}{lcccc}
\hline & & & & \\
& $\hat{\lambda}_{\mathbf{0}}^{\mathbf{i}}$ & $\mathbf{9 5} \% \mathbf{C . I}$. & $\hat{\lambda}^{\mathbf{i}}$ & $\mathbf{9 5} \%$ C.I. \\
Australia & 0.082 & $(-0.011,0.175)$ & 0.057 & $(-0.010,0.136)$ \\
Belgium & 0.038 & $(-0.016,0.092)$ & 0.014 & $(-0.009,0.065)$ \\
Canada & 0.069 & $(-0.021,0.159)$ & 0.041 & $(-0.020,0.114)$ \\
Denmark & 0.067 & $(-0.041,0.175)$ & 0.029 & $(-0.034,0.112)$ \\
France & 0.037 & $(-0.026,0.100)$ & 0.004 & $(-0.015,0.074)$ \\
Germany & 0.071 & $(-0.025,0.167)$ & 0.045 & $(-0.016,0.114)$ \\
Ireland & 0.066 & $(-0.024,0.156)$ & 0.036 & $(-0.015,0.110)$ \\
Italy & 0.029 & $(-0.034,0.092)$ & 0.003 & $(-0.014,0.057)$ \\
Japan & 0.046 & $(-0.041,0.133)$ & 0.014 & $(-0.034,0.083)$ \\
The Netherlands & 0.065 & $(-0.043,0.173)$ & 0.028 & $(-0.030,0.111)$ \\
Norway & 0.045 & $(-0.036,0.126)$ & 0.008 & $(-0.024,0.075)$ \\
South-Africa & 0.120 & $(-0.006,0.246)$ & 0.094 & $(-0.002,0.187)$ \\
Spain & 0.029 & $(-0.025,0.083)$ & 0.001 & $(-0.027,0.054)$ \\
Sweden & 0.095 & $(-0.013,0.203)$ & 0.068 & $(-0.008,0.147)$ \\
Switzerland & 0.117 & $(-0.009,0.243)$ & 0.095 & $(-0.002,0.177)$ \\
UK & 0.073 & $(-0.044,0.190)$ & 0.029 & $(-0.032,0.123)$ \\
US & 0.085 & $(-0.026,0.196)$ & 0.060 & $(-0.007,0.137)$ \\
& & & & \\
\hline
\end{tabular}


Table 3: Speed of mean reversion for individual countries (different benchmarks)

This table reports country-specific estimates of the speed of mean reversion, based on different benchmark indexes (US, Japan, France, and Germany). The sample period covers the years 1900-2008. The biased SUR estimate of the speed of mean reversion is given (' $\lambda_{0}^{i}$ '), as well as the median-unbiased estimate (' $\lambda^{i}$ ') based on the bootstrap approach. Also a corresponding $95 \%$ confidence interval for $\hat{\lambda}^{i}$ is provided (' $95 \%$ C.I.).

\begin{tabular}{|c|c|c|c|c|c|c|}
\hline & $\hat{\lambda}_{0}^{i}$ & $\hat{\lambda}^{i}$ & 95\% C.I. & $\hat{\lambda}_{0}^{i}$ & $\hat{\lambda}^{i}$ & 95\% C.I. \\
\hline Benchmark: & US & & & Japan & & \\
\hline Australia & 0.130 & 0.094 & $(-0.014,0.199)$ & 0.044 & 0.012 & $(-0.022,0.081)$ \\
\hline Belgium & 0.040 & 0.014 & $(-0.007,0.069)$ & 0.076 & 0.046 & $(-0.021,0.127)$ \\
\hline Canada & 0.077 & 0.058 & $(-0.029,0.137)$ & 0.045 & 0.015 & $(-0.028,0.076)$ \\
\hline Denmark & 0.064 & 0.028 & $(-0.026,0.121)$ & 0.063 & 0.023 & $(-0.036,0.109)$ \\
\hline France & 0.040 & 0.007 & $(-0.014,0.057)$ & 0.083 & 0.045 & $(-0.030,0.135)$ \\
\hline Germany & 0.072 & 0.036 & $(-0.012,0.116)$ & 0.081 & 0.049 & $(-0.025,0.133)$ \\
\hline Ireland & 0.065 & 0.042 & $(-0.010,0.117)$ & 0.089 & 0.063 & $(-0.018,0.142)$ \\
\hline Italy & 0.031 & 0.005 & $(-0.014,0.053)$ & 0.063 & 0.036 & $(-0.017,0.103)$ \\
\hline Japan & 0.045 & 0.020 & $(-0.027,0.087)$ & & & \\
\hline The Netherlands & 0.072 & 0.046 & $(-0.029,0.105)$ & 0.052 & 0.006 & $(-0.045,0.098)$ \\
\hline Norway & 0.044 & 0.006 & $(-0.022,0.067)$ & 0.071 & 0.034 & $(-0.031,0.115)$ \\
\hline South-Africa & 0.137 & 0.109 & $(0.020,0.199)$ & 0.053 & 0.018 & $(-0.025,0.098)$ \\
\hline Spain & 0.029 & 0.004 & $(-0.018,0.049)$ & 0.077 & 0.051 & $(-0.021,0.117)$ \\
\hline Sweden & 0.126 & 0.094 & $(0.002,0.189)$ & 0.054 & 0.020 & $(-0.022,0.090)$ \\
\hline Switzerland & 0.099 & 0.070 & $(-0.008,0.155)$ & 0.065 & 0.032 & $(-0.024,0.107)$ \\
\hline UK & 0.078 & 0.045 & $(-0.014,0.122)$ & 0.068 & 0.038 & $(-0.031,0.114)$ \\
\hline US & & & & 0.045 & 0.012 & $(-0.030,0.078)$ \\
\hline Benchmark: & France & & & Germany & & \\
\hline Australia & 0.042 & 0.012 & $(-0.011,0.077)$ & 0.059 & 0.031 & $(-0.013,0.098)$ \\
\hline Belgium & 0.205 & 0.169 & $(0.002,0.193)$ & 0.075 & 0.041 & $(-0.034,0.125)$ \\
\hline Canada & 0.041 & 0.009 & $(-0.014,0.077)$ & 0.064 & 0.034 & $(-0.017,0.106)$ \\
\hline Denmark & 0.068 & 0.033 & $(-0.022,0.111)$ & 0.077 & 0.050 & $(0.050,0.124)$ \\
\hline France & & & & 0.072 & 0.031 & $(-0.029,0.118)$ \\
\hline Germany & 0.072 & 0.039 & $(-0.039,0.125)$ & & & \\
\hline Ireland & 0.077 & 0.040 & $(-0.030,0.129)$ & 0.091 & 0.062 & $(-0.021,0.145)$ \\
\hline Italy & 0.081 & 0.036 & $(-0.041,0.145)$ & 0.059 & 0.024 & $(-0.043,0.098)$ \\
\hline Japan & 0.083 & 0.039 & $(-0.032,0.149)$ & 0.081 & 0.049 & $(-0.025,0.138)$ \\
\hline The Netherlands & 0.043 & 0.002 & $(-0.028,0.081)$ & 0.082 & 0.052 & $(-0.024,0.136)$ \\
\hline Norway & 0.179 & 0.145 & $(0.006,0.195)$ & 0.067 & 0.027 & $(-0.027,0.117)$ \\
\hline South Africa & 0.045 & 0.011 & $(-0.015,0.080)$ & 0.063 & 0.030 & $(-0.021,0.105)$ \\
\hline Spain & 0.136 & 0.105 & $(-0.014,0.199)$ & 0.071 & 0.039 & $(-0.026,0.118)$ \\
\hline Sweden & 0.054 & 0.018 & $(-0.011,0.088)$ & 0.078 & 0.052 & $(-0.008,0.121)$ \\
\hline Switzerland & 0.050 & 0.009 & $(-0.023,0.088)$ & 0.082 & 0.054 & $(-0.015,0.135)$ \\
\hline UK & 0.047 & 0.001 & $(-0.027,0.082)$ & 0.087 & 0.055 & $(-0.019,0.144)$ \\
\hline US & 0.040 & 0.008 & $(-0.014,0.074)$ & 0.072 & 0.042 & $(-0.014,0.120)$ \\
\hline
\end{tabular}


Table 4: Speed of mean reversion based on the panel data model

This table reports the estimated speed of mean reversion based on the panel data model for different benchmark indexes. In the panel data model the speed of mean reversion is assumed to be the same in all seventeen countries under consideration. The sample period spans the years 1900-2008. The biased SUR estimate of the speed of mean reversion is given (' $\lambda_{0}{ }^{\prime}$ ), as well as the median-unbiased estimate (' $\lambda$ ') based on the bootstrap approach. Also a corresponding $95 \%$ confidence interval for $\hat{\lambda}$ is provided (' $95 \%$ C.I.). Finally, the corresponding half-life is reported, with associated $95 \%$ confidence interval.

\begin{tabular}{lcccc}
\hline Benchmark & $\hat{\lambda}_{\mathbf{0}}$ & $\hat{\lambda}$ & $\mathbf{9 5 \%}$ C.I. & $\begin{array}{c}\text { Half-life } \\
\text { in years }(\text { C.I. })\end{array}$ \\
World & 0.0668 & 0.0491 & $(0.0323,0.0661)$ & $13.8(10.1,21.1)$ \\
US & 0.0699 & 0.0523 & $(0.0353,0.0697)$ & $12.9(9.6,19.3)$ \\
Japan & 0.0714 & 0.0521 & $(0.0304,0.0713)$ & $13.0(9.4,22.5)$ \\
France & 0.0708 & 0.0533 & $(0.0306,0.0718)$ & $12.7(9.3,22.3)$ \\
Germany & 0.0728 & 0.0541 & $(0.0298,0.0755)$ & $12.5(8.8,22.9)$ \\
& & & & \\
\hline
\end{tabular}


Table 5: Rolling-window estimates of the speed of mean reversion $\lambda$

This table reports rolling-window estimates of the speed of mean reversion, based on the panel data model. The rolling-window interval is reported ('Period'), as well as the biased SUR estimate of the speed of mean reversion during that period (' $\lambda_{0}$ '). Also the median-unbiased estimate is displayed (' $\lambda$ ') together with a corresponding $95 \%$ confidence interval, both based on the bootstrap approach ('95\% C.I.).

\begin{tabular}{|c|c|c|c|c|c|c|c|}
\hline Period & $\hat{\lambda}_{0}$ & $\hat{\lambda}$ & 95\% C.I. & Period & $\hat{\lambda}_{0}$ & $\hat{\lambda}$ & 95\% C.I. \\
\hline 1900 to 1926 & 0.081 & 0.030 & $(-0.029,0.086)$ & 1942 to 1968 & 0.178 & 0.151 & $(0.086,0.196)$ \\
\hline 1901 to 1927 & .084 & 029 & $(-0.031,0.088)$ & 1943 to 1969 & 0.207 & 0.177 & $(0.115,0.225)$ \\
\hline 1902 to 1928 & .085 & & $-0.030,0.083)$ & 1944 to 1970 & & & $(0.158,0.260)$ \\
\hline 1903 to 1929 & .112 & 064 & $-0.015,0.117)$ & 1945 to 1971 & & & \\
\hline 1904 to 1930 & .124 & & & 1946 to 1972 & & & $072,0.188)$ \\
\hline 1905 to 1931 & .123 & .066 & $.132)$ & & & & \\
\hline 1906 to 1932 & .124 & & & & & & \\
\hline 1907 to 1933 & 126 & .067 & $.130)$ & & 0.209 & 0.167 & $.220)$ \\
\hline & & & & & & & \\
\hline 1909 to 1935 & 139 & .081 & & & & 67 & \\
\hline & & & & & & & \\
\hline 1911 to 1937 & .150 & .094 & & & & & \\
\hline & & & & & & & \\
\hline 1913 to 1939 & .171 & 120 & & & & & \\
\hline & .237 & & & & & & \\
\hline 1915 & .237 & 185 & & & .191 & 0.141 & \\
\hline & .252 & & & & & & \\
\hline 1917 to 1943 & .284 & .258 & & & & 0.174 & \\
\hline & .315 & & & & & & \\
\hline 1915 & & & & & & & \\
\hline 1920 & .244 & .178 & & & & 0.175 & 43) \\
\hline & & & & & & & \\
\hline 1922 to 1948 & .159 & .073 & & & & & 11) \\
\hline & & & & & & & \\
\hline 1924 to 1950 & .158 & .080 & & & & 0.177 & 36) \\
\hline & & & & & & & \\
\hline & .162 & .078 & & & & 0.201 & 259) \\
\hline & & & & & & & \\
\hline to 1954 & 0.174 & .096 & $.185)$ & & $\underline{0.260}$ & $\underline{0.218}$ & $.281)$ \\
\hline & & & & & & & $.288)$ \\
\hline & .153 & .075 & & & & 0.195 & $.273)$ \\
\hline 1931 & .156 & & $9,0.171)$ & 1973 to 1999 & 0.294 & & $1,0.315)$ \\
\hline & 0.150 & & & & & 0.233 & $(0.166,0.295)$ \\
\hline 1933 to 1959 & 0.151 & 0.096 & $(-0.007,0.171)$ & 1975 to 2001 & 0.250 & 0.192 & $(0.113,0.262)$ \\
\hline & 0.141 & & & & & 0.197 & $(0.121,0.272)$ \\
\hline 1935 to 1961 & 0.143 & 0.085 & $(-0.009,0.153)$ & 1977 to 2003 & 0.208 & 0.136 & $(0.052,0.215)$ \\
\hline & 0.133 & & & 1978 to 2004 & 0.188 & 0.121 & $(0.032,0.199)$ \\
\hline 1937 to 1963 & 0.146 & 0.089 & $(-0.008,0.165)$ & 1979 to 2005 & 0.175 & 0.107 & $(0.018,0.186)$ \\
\hline & 0.155 & & & 1980 to 2006 & 0.154 & 0.103 & $(0.036,0.173)$ \\
\hline 1939 to 1965 & 0.149 & 0.098 & $(-0.010,0.165)$ & 1981 to 2007 & 0.148 & 0.095 & $(0.018,0.165)$ \\
\hline & 0.148 & & $(0.010,0.165)$ & 1982 to 2008 & 0.205 & 0.166 & $(0.100,0.228)$ \\
\hline 1941 to 1967 & 0.159 & 0.129 & $(0.058,0.179)$ & & & & \\
\hline
\end{tabular}



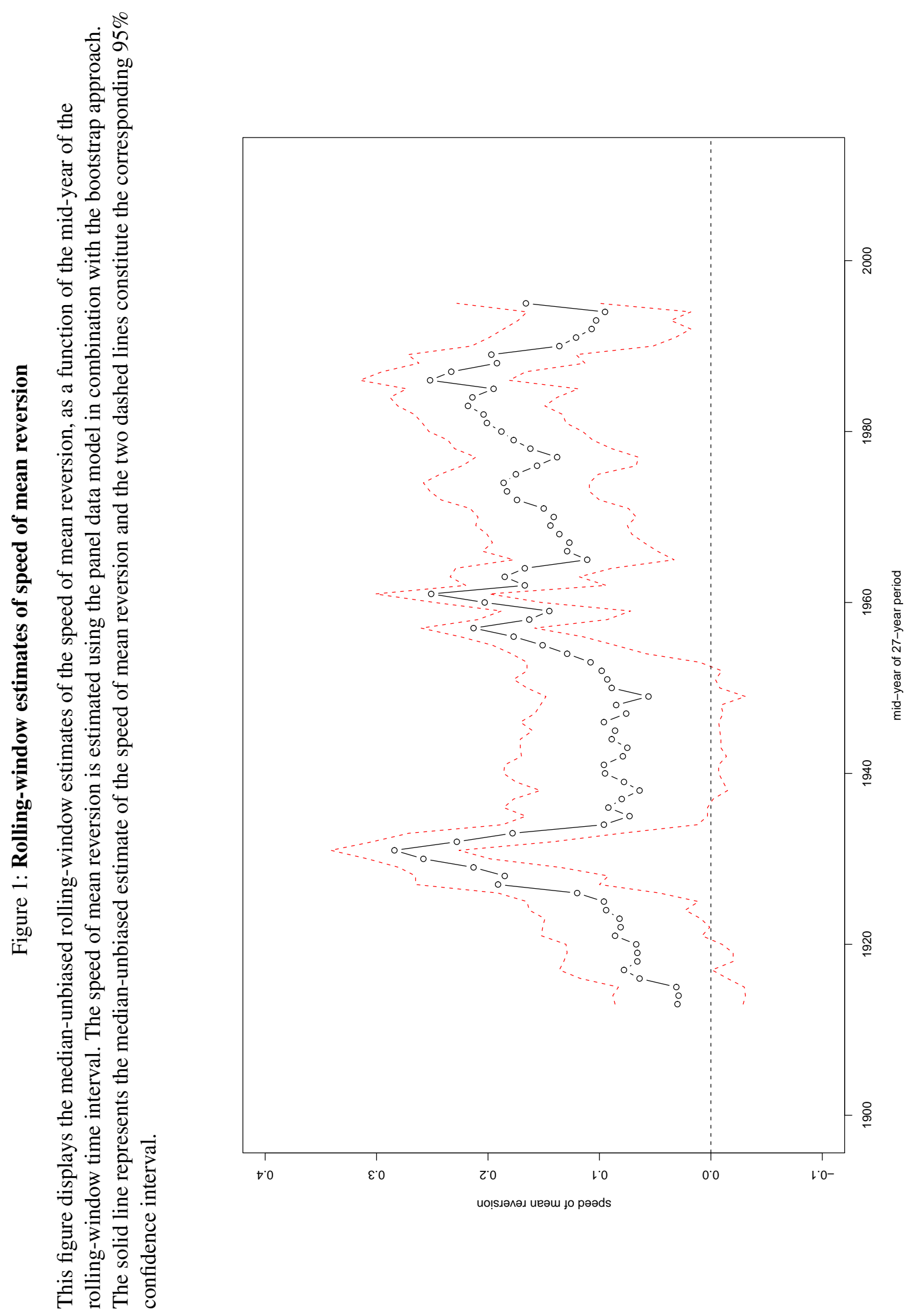

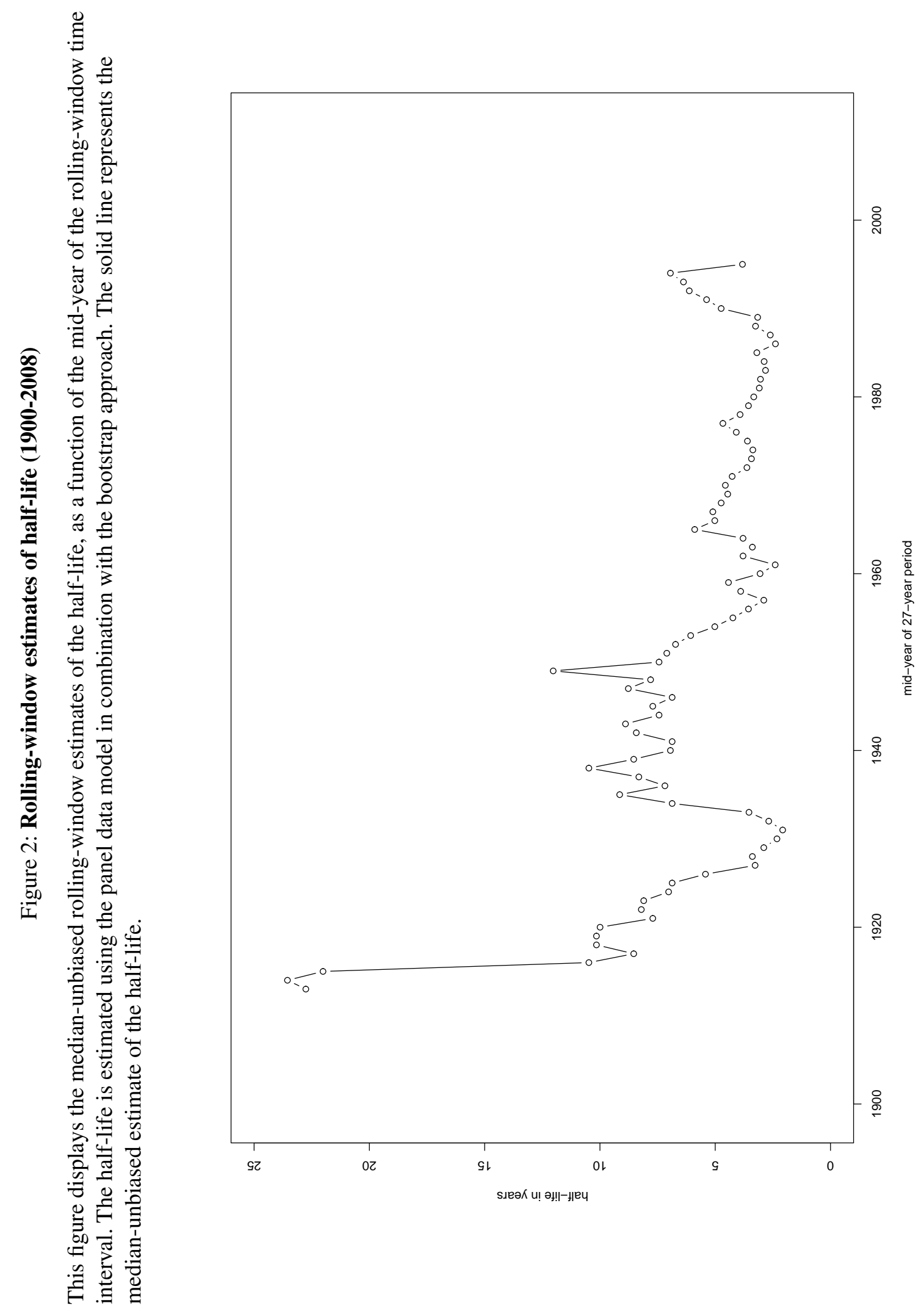

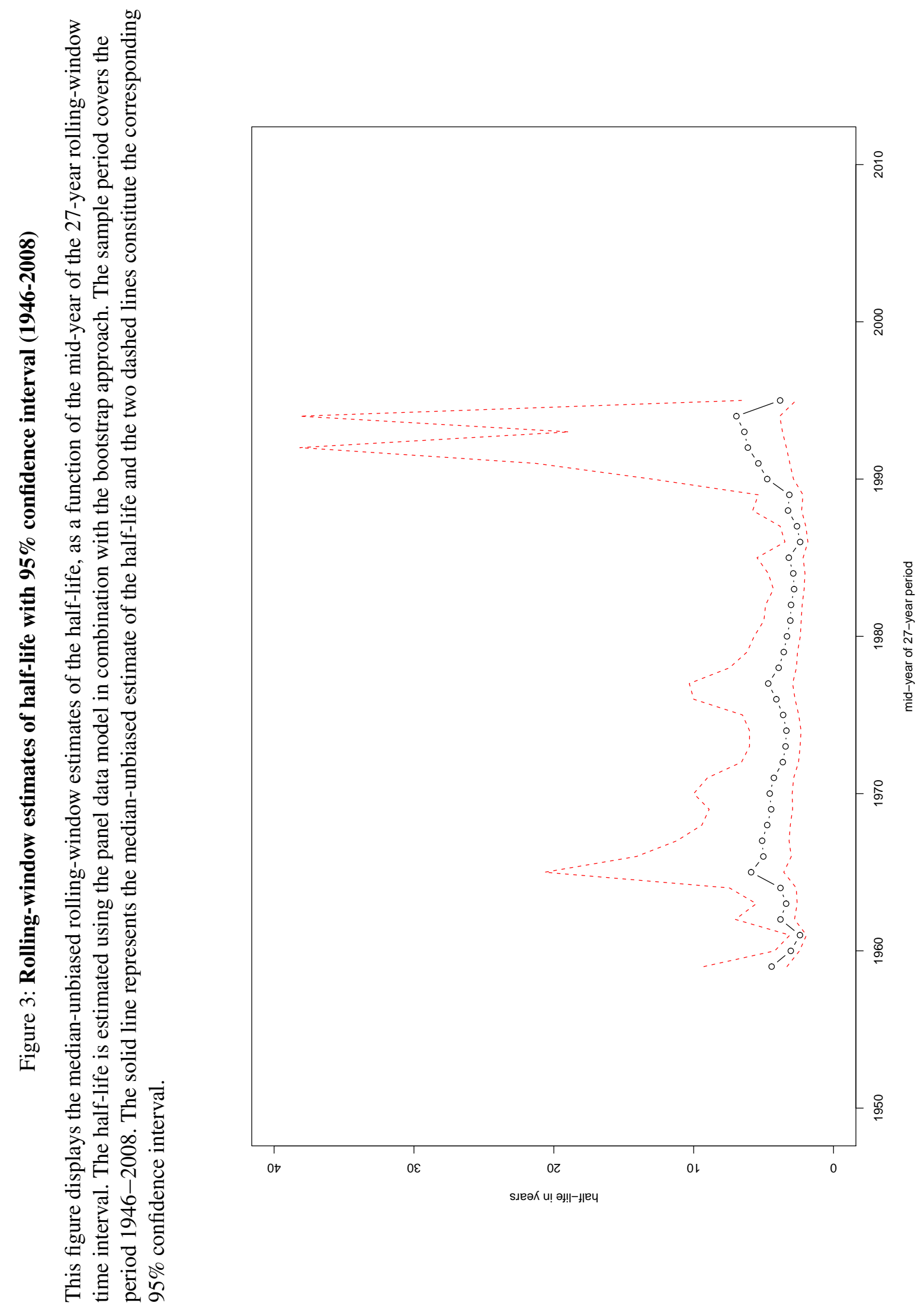


\section{Appendix A Bootstrap Method}

To test the null hypothesis $H_{0}: \lambda=0$, we estimate the remaining model parameters of Equation (4) under the null hypothesis and consider the small-sample distribution of $\hat{\lambda}$. Subsequently, we use the bootstrap to obtain the empirical small-sample distribution of $\hat{\lambda}$. The bootstrap approach to estimate the empirical small-sample distribution of $\hat{\lambda}$ under the null hypothesis that $\lambda=0$ consists of the following steps:

1. Estimate the empirical values of $\hat{\alpha}$ and $\hat{\phi}$ under the null hypothesis that $\lambda=0$, i.e. estimate the model in Equation (4), and store the residuals $\hat{\omega}$.

2. Use the residuals from Step 1 to generate the bootstrapped residuals $\hat{\omega}^{*}$ by randomly selecting $T-k$ vectors. Each vector equals a row of error terms from $N$ countries at some time instance between $t=1$ and $T-k$.

3. Recursively calculate the values of the return deviations using $\hat{\omega}^{*}$ in the model of Equation (4), under the assumption that $\lambda=0$, to arrive at a bootstrapped set of return deviations: $\left(r_{t}^{i}-r_{t}^{b}\right)^{*}$, for $t=1, \ldots, T-k$ and $i=1, \ldots, N$.

4. Apply a seemingly unrelated regression to the bootstrapped deviations to find a bootstrapped estimate $\hat{\lambda}^{*}$.

5. Repeat Step 2 to 4 a large number of times, say $B=500$, to find the empirical small-sample distribution of $\hat{\lambda}$ under the null hypothesis.

The goal of estimating the corrected lambda's and confidence bounds is twofold. First, to derive the median-unbiased half-life of the stock price deviations and the corresponding confidence bounds. Second, to compare the estimates over time to check the consistency of the speed of reversion and its significance over time. The procedure of determining the median-unbiased estimate is similar to the procedure described above, however applied to different initial values for $\lambda$. The goal is to specify the initial value $\lambda$ in such a way that the bootstrapped empirical small-sample distribution has a median equal to the original estimate $\hat{\lambda}$ from the original data. To find this 
initial value, a large range of initial speeds of reversion is considered. For each initial value $\lambda$ the bootstrapped median is compared to the empirical estimate of $\lambda$. The initial values considered are $(-0.12,-0.10, \ldots, 0.50)$, and linear interpolation is used to find the closest value for the small-sample bias corrected estimate of $\lambda$. To find the confidence bounds, the same procedure is executed, however applied to the 2.5 and 97.5 percentile. 